Portarlington, in 1866 , several thousand tons of press turf were made by a modification of the oldest known "drypress" process-that of Gwynne, which was itself tried on a small scale in 1855 at Kilberry. Of historical interest also is the fact that, of "wet-press" processes, one of the oldest found in the literature of peat is that which was employed by Williams in 1844 at Cappoge, in the Bog of Allen.

In recent years there have been built in Ireland many peat-moss litter factories, such as those at Umaras, near Monasterevan, County Kildare; at Coolaney, County Sligo; at Maghery, County Tyrone; at Ferbane and Rahan, King's County; and at Inchicore and Ringsend, in Dublin. The peat paper factory at Celbridge, County Kildare, belonging to the Callendar Paper Company, has recently been closed. At Umaras and Maghery there are peat-fuel factories, and at Kilberry a fuel called "electropeat" is manufactured. Quite recently experiments have been carried out at Carnlough, County Antrim, on the production of ammonia from peat, and the installation of a

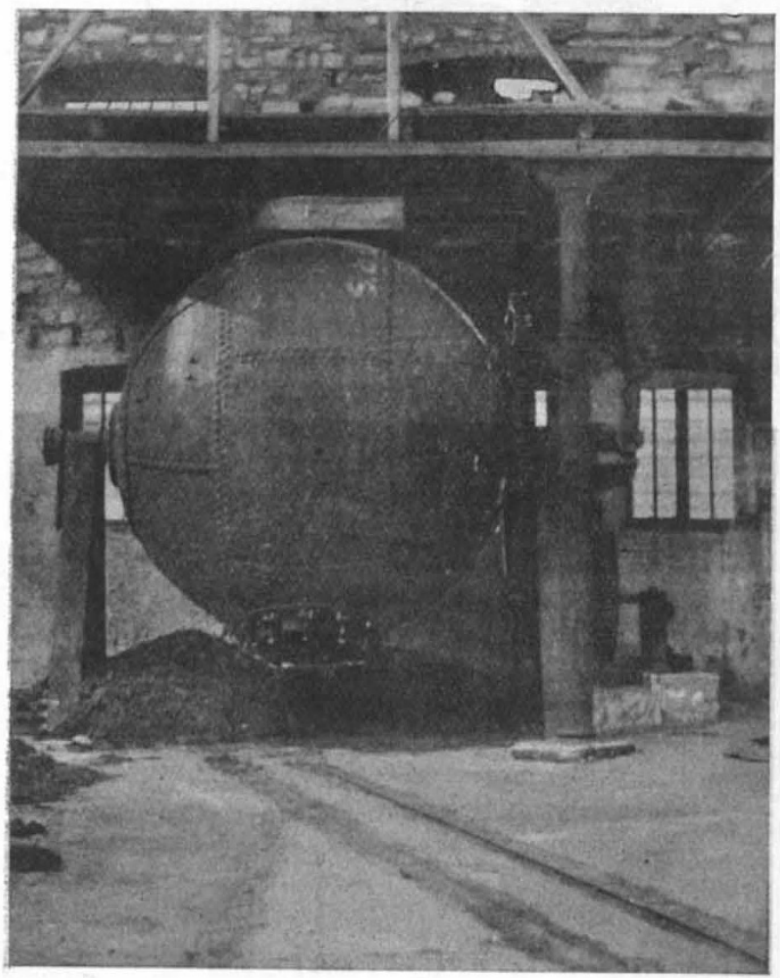

Frg. 4.-Peat digester, peat paper factory, Celbridge, co. Kildare.

plant capable of producing 5000 tons of ammonium sulphate per annum is now being completed at a cost of $85,000 l$.

It is convenient to divide the peat industries into three classes, namely, the fibre, the fuel, and the distillation industries. In this paper the first, and probably the most important, class will be considered more fully. In the peat-moss litter districts of Ireland the peat is dug out of the bog in large sods, which are dried in the air and stored under cover to prevent the re-absorption of water. The air-dried peat is next disintegrated by the rotating circular saws contained in the body of a dividing machine (so-called wolf, Fig. 2), sifted free from mould, and compressed into bales by vertical knee-lever presses, such as that used at Umaras (Fig. 3). From the "wolf," which is placed on the ground floor of the factory, the divided peat is carried by elevators to the upper floor, where, after passage through a cylindrical sieve, it is delivered into the funnel-shaped mouth of the baler. The mould can at the same time be collected apart. It is exported in large quantities by the owner of one of the factories to southern countries for the preservation and packing of fruit and vegetables grown there.

Where a suitable canal system exists the peat-litter industry is successful, but where canals are not available the industry is crippled by the high rates of carriage. charged by the railway companies.

The purified peat moss can be used for the preparation of peat molassine meal and for the manufacture of alcohol, but as the latter process can scarcely at the present time be carried on remuneratively it is not practised in Ireland.

The peat paper factory which was established in 1903 at Celbridge, and turned out large quantities of wrapping paper yearly, was unsuccessful. It was finally closed in December, 1905. The peat, brought on cars from a bog situated at a distance of several miles from Celbridge, was subjected to a preliminary treatment in a large spherical revolving digester (Fig. 4), from which it was conveyed by cars running on a small iron railway to the scarifying and beating machine, where it was converted into pulp. After passing through sand-traps, the unbleached pulp was delivered on to an endless band, by which it was brought between the revolving rollers of a paper-pressing machine. The band of paper thus formed was glazed and polished by vertical rollers.

The motive power of the factory was electricity, which was generated in a dynamo driven by a 200 horse-power turbine worked by water from the adjacent Liffey.

The brown wrapping paper sold by the company was of a strong texture, excellent quality, and contained about 66 per cent. of peat fibre. Considering, however, the large amount of material present in crude turf which is useless for the manufacture of paper, it will be readily seen that the preliminary treatment of the peat should be carried out in the immediate neighbourhood of the bog.

The accompanying illustrations from the author's "Reports upon the Irish Peat Industries," part i., are reproduced by the courtesy of the Royal Dublin Society.

Hugh Ryan.

\section{ZOOLOGY AT THE BRITISH} ASSOCIATION.

The Physical Basis of Inherithnle.

$\mathrm{NE}$ of the most interesting features programme of Section D was a discussion, jointly with Section $\mathrm{K}$, on the physichl basis inheritance. In opening the debate, Prof. H. Alickson, F.R., dissented from Mntgome ('s the inherited characters are transmitled sofe fy the chromosomes. The principal piece of ifidence which is quoted in support of this hypothesis is Boveri's experiment (1889) in which an enucleate echinoderm ovum of one species, fertilised by a spermatozoon of another species, produced a larva with purely paternal characters; but similar subsequent experiments have not always resulted in a larva with purely paternal characters. Confirmatory evidence of the theory is held to be afforded by (I) the constancy in the number of chromosomes in the somatic cells; (2) the reduction to half the normal number of chromosomes in the sexual cells; and (3) the presence of similar heterogeneous chromosomes in the sexual cells of certain Arthropods and their mutual conjugation during fertilisation. If the theory be true, it appears necessary to hold that the chromosomes maintain their individuality, but there is convincing evidence that in some animals this is not the case, e.g. in certain Rhizopoda (e.g. Pelomyxa), Suctoria (e.g. Ephelota, Dendrosoma), and Coelenterates. Moreover, if it be true that the cytoplasm of conjugating cells is not concerned in the transmission of hereditary characters, it is difficult to account for the long duration of the period of conjugation in Infusoria and the cases of fertilised enucleate eggs which produced larvæ with maternal characters. Prof. Hickson sukgested a possible explanation, viz. that where the characters are comparatively rigid, as in mammals, insects, and some other groups, they are aggregated in definite masses, and may be associated with the chromosomes, but where it is advantageous for the characters to remain more variable they

NO. I977, vOL. 767 
are associated with the cytoplasm, as in the Protozoa and some Cœlenterates.

Prof. J. B. Farmer, F.R.S., said that although the chromosomes are probably not the actual bearers of the hereditary characters, they may produce their results by acting upon some specific substance in the protoplasm of the cell. He pointed out that the behaviour of the chromosomes in the heterotype division, preceding the formation of sexual cells, provides an arrangement for the sorting out of characters such as is shown to occur by breeding experiments. The chromosomes themselves consist of congeries of smaller entities-the chromomeres-which are probably very numerous; possibly it is these smaller entities which are associated with the hereditary characters. Such an assumption would answer the often raised objection that the characters exhibited by an organism are more numerous than the chromosomes. In any case, the heterotype division provides a mechanism for arranging these entities on a mathematical basis. The development of an organism on certain definite lines is the result of interaction of the nucleus and cytoplasm, and as there is no mechanism apparent in the cytoplasm for the sorting out of characters, while such is present in the nucleus, it seems reasonable to associate the latter with the carrying of the hereditary characters. Moreover, in many cases only the nucleus of the spermatozoon enter the egg during fertilisation, and yet the parental characters are conveyed.

Mr. R. C. Punnett pointed out that in the interpretation of the facts of heredity the student of genetics has been led to the conception of factors in the gametes upon which his unit characters are based. Between the postulated behaviour of these factors in segregation and the observed behaviour of the chromosomes in the divisions of the germ-cells there is a striking agreement. Nevertheless, certain cases of dihybridism offer phenomena pointing to the existence of gametic series in which the four types of gametes are produced, not in equal numbers, but in such ratios as $7: 1: 1: 7$ or $15: 1: 1: I_{5}$. If the cytologist desires to regard the chromosomal elements as the physical basis of heredity, he must provide some scheme which will include these phenomena.

Prof. V. H. Blackman stated his belief in the chromatin as an active agent in the process of heredity. Boveri's work on the multiple fertilisation of echinoderm eggs seems to indicate that not only do the chromosomes carry the hereditary properties, but also that they are physiologically differentiated. The speaker suggested that in the protozoan nucleus there is a duplication or even a multiplication of the parts, and that it is not necessary for the whole nucleus to divide or for chromosomes to be evident; a portion of the nuclear substance pinched off may contain representatives of each of the characters.

Mr. R. P. Gregory pointed out that in all the somatic cells the division of the nucleus shows a certain form of symmetry, whereas just previous to the formation of gametes this symmetry is replaced by another-the heterotype division. From experiments in regeneration and vegetative propagation, it appears that all the characters are distributed throughout all the cells of the organism, whereas breeding experiments show that segregation takes place on the formation of gametes, one form of symmetry being replaced by another in precisely similar manner to that indicated by the study of the nucleus. It is impossible to believe that this is a mere coincidence.

Mr. A. D. Darbishire said he would only attempt to answer one question, viz., Are there any characters which depend for their manifestation on factors which exist in the cytoplasm? His observations on the starch grains in peas afford an affirmative answer. The difference between round and wrinkled peas depends largely on the nature of the starch grains. In round peas the grains are potatoshaped, in wrinkled peas they are round in contour and compound. In the hybrid the grain is intermediate between those of the parents in three respects:-(x) in contour; (2) in compoundness, about half the grains being simple and half compound; (3) in the number of pieces in the compound grains, which is usually three, rarely two (in non-hybrids it is six). As is well known, the formation of starch grains depends upon certain plastids produced, not by the nucleus, but from others previously existing in the cytoplasm.
Mr. L. Doncaster held that the maternal characters in the hybrid larvæ referred to by Prof. Hickson were only found in the very early stages, and could not properly be called hereditary characters. He suggested that the abnormal behaviour of the nucleus in the Protozoa might be associated with their great simplicity of organisation, no differentiation of chromosomes bearing hereditary characters having yet taken place.

Prof. M. M. Hartog said that the essential part of the chromosome in heredity appeared to be, not the chromatic elements, but the achromatic basis, a view advocated also by Boveri. He thought it was futile to attempt to exclude the cytoplasm from the genuine basis of heredity. With reference to the suggestion, made earlier in the discussion by $\mathrm{Mr}$. C. C. Hurst, that cytologists should investigate the relations between the nucleus and the external characters of crosses, Prof. Hartog was inclined rather to request breeders to investigate certain forms exhibiting exceptional cell divisions. In at least two species of Tradescantia single chromosomes are often left out in the heterotype division of the pollen, and appear finally to be digested. In several species of Hemerocallis at the same stage the chromosomes are distributed into either three or four cells, and the pollen grains are consequently irregular in size, in number, and in the chromosomes they contain.

Prof. Hickson, in replying to the criticisms, regretted that there was not time to traverse them in detail Referring to Wilson's work on the heterogeneous chromosome in the nucleus of the testis cells of Anasa tristis, he pointed out that Foote and Strobell deny the presence of such a chromosome. If, as was asserted during the discussion, specimens of this animal from some localities possess this chromosome while others from a different locality do not, that is a strong argument against the allpowerful influence of the chromosomes in regard to the hereditary characters.

\section{The Experimental Study of Heredity.}

Mr. R. C. Punnett illustrated his lecture on this subject by a series of actual examples, drawn chiefly from fowls and sweet-peas. He pointed out that the laws of heredity associated with the name of Mendel apply equally to plants and animals; the comb of the fowl, the stature of the sweet-pea, the colour of the stock, the hair of the rabbit, rust immunity in wheat, and some diseases in man, all conform to the same laws of heredity. Experimental work with animals may well lead to a solution of many problems in human disease; but, important as are the practical results, this study has a still greater importance in relation to our scientific conceptions, for it must radically affect our views of the process of evolution, the nature of mutation, and the physical basis of heredity.

\section{Protozoa.}

Mr. F. B. Rowley exhibited a series of models of Protozoa-Amœba, Vorticella, Paramœcium, Actinosphærium, and the parasite of human malaria in blood corpuscles-constructed chiefly of gelatin, which give an excellent idea of the appearance of these organisms in life.

Mr. H. B. Fantham discussed the classification of the Haplosporidia. He and Dr. Ridewood suggest the division of the group into two sections:-

(1) Polysporulea, in which the pansporoblast gives rise to nine or more spores, e.g. Rhinosporidium, Neurosporidium.

(2) Oligosporulea, in which the pansporoblast gives rise to a few (four) spores or to a single spore, e.g. Haplosporidium, Bertramia, Coelosporidium.

\section{The Movements of Spirochaetes.}

Mr. Fantham pointed out that the nature of the movements of Spirochætes would serve as an aid in separating this genus from Spirillum. Knowledge of these movements would therefore be of value in connection with the vexed question of the nature of the organism of relapsing fever. Spirochretes, especially $S$. anodontae, with its: pointed ends, usually move very rapidly, but in slowly moving specimens the organism can be seen to move forward while turning on its long axis. The motion can be 
resolved into two components:-(I) a vibratory motion of flexion of the body mainly for progression; (2) a spiral motion of the body as a whole due to the undulating membrane-a spirally wound lateral extension of the ectoplastic periplast bearing striations (the contractile myonemes). The body of a Spirillum bears flagella, and is more rigid than that of a Spirochæte in motion. The so-called flagellate (ciliate) stages of Spirochætes are merely due to the splitting off of myoneme fibrils from the undulating membrane during its rupture, resulting from violent contortions or approaching death.

\section{Some Points in the Structure of the Larva of Lanice conchilega.}

The Rev. G. A. Elrington described, in the pelagic larva of Lanice conchilega, a gland situated on the dorsal side of the œesophagus, and composed of a cluster of large pearshaped cells, the thin ends of which converge to the orifice of the giand, which lies in the mid-dorsal line of the "neck" region. From its staining reactions it is evident that the gland is concerned in secreting the mucin of the gelatinous tube in which the larva is found enclosed. The gland, which is not present in the adult or in a young worm which was just beginning to form its sandy tube, is evidently a transitory structure, which persists only so long as the larva retains its transparent tube. In the pelagic larva there are three separate nephridia, there being no trace of the fusion characteristic of the nephridial apparatus of the adult.

Mr. Arnold T. Watson expressed the opinion that the gelatinous tube, in which the larva floats, not only serves as a protection, but is also the means of collecting food particles, which on being brought into contact with the outside of the tube adhere to it. In order to secure this food the larva from time to time partially emerges from one end of the tube and applies to its surface the ciliated groove which runs from end to end of its growing tentacles. Development of the organism is thus carried on to a stage further than would have been possible in the absence of solid food. By the time the animal settles down on the sea-bottom and begins to construct the membranous sand-covered tube inhabited by the adult, the mucus-secreting gland, being no longer required, disappears, and owing to its dorsal position does so without disturbing the formation of the permanent ventral glandular structures which produce the membranous basis of the tube of the adult.

\section{The Development of Ophiothrix fragilis.}

Prof. E. W. MacBride, F.R.S., described the early stages of development of this common British Ophiurid. Two sets of cultures were studied, the first obtained by fertilising the eggs artificially, the second by allowing the ripe male and female naturally to shed their reproductive products. In the first series, segmentation resulted in the formation of a morula, an invagination followed, and it then transpired that the interior cells were precociously formed mesenchyme. The cœlom appeared as a single vesicle at the apex of the gut. In the second series segmentation resulted in the formation of a thick-walled blastula, followed by a regular invagination. At the pole of the larva opposite the blastopore a great crest of vacuolated cells-serving as a float-was formed. (This crest was not seen in the larve of the first series.) The larva then assumed a triangular form, the cœilom appeared at the apex of the archenteron as a bilobed vesicle, and the crest slowly diminished in size. The coelomic vesicle divided into right and left halves; of these, first the left, then the right, divided into anterior and posterior parts. Somewhat later, from the anterior portion of the vesicle of both sides a sac was budded off; that of the left side became five-lobed, and gave rise to the water-vascular system; that of the right side generally remained small, but sometimes also assumed the five-lobed form, showing that it is a rudimentary fellow of the watervascular system. The larva of Ophiothrix fragilis affords final and convincing proof that the echinoderm larva possesses three somites, the middle one of which becomes, on the left side, the water-vascular system.

The differences in the early phases of development of the two series above described are probably attributable to the fact that the eggs withdrawn from the female and artificially fertilised were not quite ripe, and therefore not quite of the same chemical composition as those naturally shed. In certain features the development of the artificially fertilised eggs resembles that of Ophiothrix brevis, a species with shortened development, a fact which leads the author to ask if mutations may not be due to slight chemical differences in ova at the moment of fertilisation.

\section{Sex in Crustacea, and the Nature of Hermaphroditism.}

Mr. Geoffrey Smith's studies upon parasitic castration show that animals belonging to widely different phyla, but especially Crustacea, when attacked by various parasites, undergo an alteration in their sexual nature. At first the gonad in both sexes degenerates to a greater or less extent; the males assume in varying degrees the secondary sexual characters proper to the female, while those of the male practically disappear; the fcmales, without assuming any male characters, suffer a certain amount of degeneration of the secondary characters, e.g. the ovigerous appendages. Finally, either on recovery from the parasite or during the degenerative process, the male may develop ova of large size in the testis, alongside mature spermatozoa. The females never produce spermatozoa in their ovaries. These results, which apply especially to the cffects of the parasitic Rhizocephala upon the crabs they infect, show that hermaphroditism can be called forth by an external cause acting upon a sexually differentiated animal, and that it can only be called forth in the male, not in the female. A partial temporary hermaphroditism is assumed by other Crustacea (e.g. the crayfish, spider-crab, and Orchestia) at particular seasons when a period of growth, as opposed to one of reproduction, is being initiated. The conclusion that hermaphroditism is a property of the male sex, developed in response to altered conditions of metabolism, can be applied to this state as found normally in Cirripedes and parasitic Isopods, both of which lead a sessile, inactive existence when adult, and have their vegetative functions devcloped to a high degree. In the parasitic Isopods all the individuals are at first free-swimming males, which, on settling down to their parasitic life, develop the hitherto latent female part of their organisation. The presence in some Cirripedes of males which may degenerate completely, even in the larval stage, and other facts, suggest that all the individuals are primarily males and subsequently females.

Mr. F. A. Potts confirmed Mr. Smith's results from his study of the effects of Peltogaster on the hermit-crab, in which also the assumption of the character of the opposite sex is confined to the male. Especially interesting is the appearance, in parasitised males, of the tufts of hair modified for egg-bearing, and the testes in many cases contain ova.

Experiments on Seasonally Dimorphic Forms of African Lepidoptera.

Dr. F. A. Dixey stated that it is often found that the successive broods of Lepidoptera produced in the course of a year differ widely in appearance according to the meteorological conditions prevailing during their immature stages, the contrast being especially marked where there is a sharp distinction between the periods of rain and dry weather. Mr. Guy Marshall, working at Salisbury, in Mashonaland, has succecded in showing that, by artificially varying the conditions to which the butterflies are exposed during their immature stages, it is possible to bring about in the midst of one season the emergence of a form which under natural conditions would only have been produced in the other. The period during which the animal is susceptible to climatic influences varies in different species, the critical stage being in some cases confined to the larval. in others to the pupal, condition. In one instance (Belenois severina) the effect of moisture combined with heat differs entirely from the effect of the former alone.

The Function of the Spiracles in Sharks and Rays.

Mr. A. D. Darbishire concludes that in the dog-fish water is drawn into the pharynx by way of the spiracles, and to some extent by the mouth, and is expelled through 
the gill clefts. In the skate the spiracles play a more important part, for when the animal is at rest all the water which enters the pharynx does so by way of the spiracles; none enters by the mouth. In Rhina squatina (the angel-fish) no movement of the spiracles is visible; there is a uniform current of water into the mouth and spiracles, and the water is driven out again through the gill slits by the undulations of the "gill covers."

The Systematic Position of Polypterus.

Mr. E. S. Goodrich pointed out that Polypterus and Calamoichthys, both from the rivers of tropical Africa, forming the order Polypterini, have no near relations among living fish. The presence of rhomboid ganoid scales, paired gular plates, a persistent spiracular gill cleft, true clavicles, a bilobed air-bladder, and a straight tail, form a combination unknown in any other order. Owing to their lobate pectoral fins, paired gulars, rhomboidal scales, outwardly diphycercal tail, and to a considerable resemblance in the disposition of the roofing cranial bones, Huxley (1861) placed the order Polypterini in the group Crossopterygii, in which it has been left by subsequent writers, associated with such extinct forms as Osteolepis and Holoptychius; but on comparing Polypterus with these fossils the resemblance is by no means close. The similarity in arrangement of the surface bones of the skull is only general, and such as may be found in most primitive Teleostomes. The scales of Polypterus and Osteolepis are of very different structure, those of the former being of the true ganoid type. The tail is not truly diphycercal, but of a modified heterocercal type, the notochord, in the young at any rate, being turned upwards (as shown by Budgett). In Actinopterygii there may occur a median ventral gular plate as well as two lateral series; two of the anterior plates of the lateral series may be more or less enlarged, as in Palæoniscidæ: the paired plates of Polypterus may be the homologues of these plates of the Actinopterygii, and not of the more median plates of the Crossopterygii. The skeleton of the pelvic fin and girdle of Polypterus is much more actinopterygian than crossopterygian in structure. The resemblance of the fins of Polypterus to the lobate fins of the Crossopterygii was shown by Budgett to be superficial only. The relationship of Polypterus to the Actinopterygii is supported by a comparison of the structure of the scales and of the fins, by the presence of large solid otoliths in the ear, and the double nostrils on each side of the snout, while the brain, the alimentary canal with its pyloric cacum, the kidneys and testes, the separate anus and urinogenital apertures, are also consistent with this view.

Colour Variations in the Skin of the Hamster.

Prof. Simroth (Leipzig) exhibited a series of skins of the hamster (Cricetus frumentarius), which is common in the corntields of some parts of Germany, and especially in Thuringia. The usual coloration of the skin is grey along the back and black ventrally, these two being separated by a lateral reddish area, and there are three white or pale yellow patches at the sides of the head and breast. The skins, however, show great variations in coloration. In one series the red areas and then the white patches disappear, the upper side becomes grey, greyish-brown, and finally black, so that the whole skin is now black. In another series the under side becomes lighter, followed by a similar change on the upper side, leading finally to an albino, the rarest variation. The black specimens were first noticed during the hot summers some years ago. It is not yet clear whether these colour variations are to be attributed to climatic conditions or are atavistic.

\section{Photographs of a Young Living Okapi.}

Sir E. Ray Lankester, K.C.B., F.R.S., exhibited photographs of a living okapi taken by Signor Ribotti at Bambili, on the Welle River, in the Congo Free State. The animal is a young colt showing the striping of the upper part of the fore and hind legs and hind quarters, and the dark body colour, apparently as in the adult. It is worthy of note that this is the first time that a European has seen a living specimen of the okapi. Some doubt having been recently expressed as to whether okapi is the native name of the animal, Sir E. Ray Lankester remarked that he had shown the photographs and a portion of a skin to some of the African pygmies, now in London, who recognised them, and at once spoke of them under the name okapi.

\section{Plankton Investigations off the Isle of Man.}

Prof. Herdman gave an account of his plankton investigations off Port Erin during April. These were undertaken with the object of testing different kinds of open and closing tow-nets, and of gaining information regarding the detailed distribution of the organisms according to locality, depth, and date. Examples were given of very different results, quantitative and qualitative, obtained from quite similar nets hauled not far apart as regards both distance and time. Sudden variations in the vertical and horizontal distribution of the plankton were discussed, and the seasonal changes were also considered; obviously great care and much observation of the gatherings of organisms are required before these can be considered as adequate samples. Prof. Herdman concluded that our methods must be investigated before the attempt to investigate nature on a large scale can be made, and also that an intensive study of small, well-chosen areas is necessary before conclusions can be drawn with regard to relatively large regions such as the North Sea or the Atlantic Ocean.

Mr. W. E. Collinge traced the rise, and pleaded for the due recognition, of economic biology; Prof. Simroth gave an account of his pendulation theory in relation to geographical distribution; Mr. J. W. Jenkinson described his further experiments on the development of the frog Mr. T. V. Hodgson pointed out the principal features of interest in the collections. of Pycnogonids from several Antarctic expeditions; and Prof. R. J. Anderson detailed his observations on the thickness of the skull in Mammalia; but these papers cannot be well summarised in the space here available. J. H. Ashworth.

\section{PHYSIOLOGY AT THE BRITISH} ASSOCIATION.

THE physiological section has for several years devoted one morning to some subject of general interest. This policy was inaugurated at 10 Town by the discussion on the effect of climg e upon health; it was followed up at York by of the physiological minimum 1 and this year at Leicester by one on the physiongical and therapeutical value of alcohol. The interes which this subject has aroused of late made it a parficularly appropriate one, more especially as the matter has not been recently discussed in at all a dispassionate way. From this point of view the meeting at Leicester was all that could be desired, and perhaps the most remarkable feature in connection with it was the very narrow margin which separated those who took different views as to the value of alcohol.

The discussion was opened by Prof. Cushny, F.R.S., who reviewed the effect of alcohol on the various systems of the body, alluding especially to its very doubtful effect as a stimulant to the alimentary system, its effects upon the circulation, especially the heart, as recently worked out by Prof. Dixon, and its action upon the muscular nervous system and on the power of the body to resist toxic agents. In doing so he introduced some of the subsequent speakers. Dr. Rivers gave an extremely interesting account of the use of the ergograph in obtaining records of the effect of alcohol. It was very remarkable to see how great was the psychical element in ergograph tracings; this, indeed, was so marked that much the same effect could be obtained by giving a dose of alcohol and one which the patient thought was alcohol, or even one which merely excited his curiosity. Dr. Rivers has been able, in conjunction with Prof. Dixon, to administer considerable doses of alcohol in forms which were not recognisable, and in doing so he has found no certain beneficial effect on the power of performing muscular work. Some curves shown by Dr. Waller, F.R.S., were quite in harmony with this view. These 